\title{
The chronic cardiovascular risk factor syndrome (Syndrome X): mechanisms and implications for atherogenesis
}

\author{
S.C. Bain and P.M. Dodson
}

Departments of Medicine and Endocrinology, East Birmingham Hospital and University of Birmingham, UK

\section{Introduction}

Although high blood pressure is a well recognized risk factor for coronary artery disease (CAD) it has been difficult to demonstrate that treatment of hypertension leads to improved cardiovascular morbidity and mortality. ${ }^{1}$ Similarly, there is no evidence that good glycaemic control in patients with non-insulin dependent diabetes mellitus reduces the development of CAD, a major cause of premature death in this group. ${ }^{2}$ In 1988 Gerald Reaven proposed that these findings may be explained if the conditions are seen in the setting of a syndrome. He proposed that the term 'Syndrome X' should be applied to a series of related variables that are important in the genesis of CAD. ${ }^{3}$ These include insulin resistance, hyperinsulinaemia, abnormal glucose tolerance, increased plasma very low density lipoprotein (VLDL) triglyceride, decreased high density lipoprotein (HDL)-cholesterol and hypertension (Figure 1). Further, he proposed that insulin resistance was causal in the syndrome. This article reviews the background to Reaven's hypothesis, the evidence in support of it and its problems, which still require explanation. The important therapeutic implications are also discussed.

- Insulin resistance

* Hyperinsulinaemia

* Glucose intolerance

* Increased VLDL triglyceride

- Decreased HDL cholesterol

- Hypertension

Figure 1 Components of Syndrome $X$ (the chronic cardiovascular risk factor syndrome).

Correspondence: P.M. Dodson, M.D., M.R.C.P., Department of Medicine, East Birmingham Hospital, Bordesley Green East, Birmingham B9 5ST, UK.

\section{Insulin resistance}

The term 'insulin resistance' refers to the level of insulin-stimulated glucose uptake measured in vivo. A common experimental method used to assess insulin resistance is the euglycaemic hyperinsulinaemia clamp. ${ }^{4}$ In this technique insulin is infused intravenously so as to produce a hyperinsulinaemic state whilst glucose is infused to maintain a predetermined level of euglycaemia. The rate of glucose infusion required to maintain a given plasma glucose level will depend upon the rate of insulin-stimulated glucose disposal in peripheral tissues. Subjects who are insulin-resistant require less glucose to be infused to maintain euglycaemia than those subjects who are sensitive to the effects of insulin. Resistance to insulin-stimulated glucose uptake is also inferred from the level of fasting insulin and the insulin response to a glucose challenge. ${ }^{5}$

Insulin resistance, hyperinsulinaemia and abnormal glucose tolerance

Resistance to insulin-stimulated glucose uptake is a common phenomenon and a characteristic finding in patients with non-insulin-dependent diabetes mellitus (NIDDM) and impaired glucose tolerance (IGT) ${ }^{6-8}$ However, the degree of insulin resistance in these conditions bears little relation to fasting glucose levels. ${ }^{9}$ Indeed, $25 \%$ of obese subjects with normal glucose tolerance may be as insulin-resistant as patients with IGT or NIDDM. ${ }^{10}$ Reaven has suggested that the explanation for varying degrees of glucose intolerance in subjects with similar insulin resistance is a compensatory secretion of insulin by the pancreas. Patients with normal glucose tolerance and insulin resistance are able to secrete large amounts of insulin and maintain a state of hyperinsulinaemia. If this compensatory state cannot be maintained then insulin levels fall (but may remain within the 'normal 
range') and subjects then develop glucose intolerance and may progress to overt NIDDM.

This hypothesis implies that the difference between subjects with NIDDM and IGT is simply the ability of pancreatic beta cells to overcome peripheral insulin resistance. It would explain the varying insulin levels reported in subjects with NIDDM (from hyperinsulinaemic to hypoinsulinaemic $^{11}$ ) and raises the possibility that correction of hyperglycaemia in subjects with NIDDM might be of limited benefit, since the underlying insulin resistance remains. In support of this concept, there are data documenting a greater insulin response to a glucose load in subjects with mild fasting hyperglycaemia compared to those with more severe NIDDM. ${ }^{12}$ Similarly, prospective longitudinal studies from a population at high risk of NIDDM (Pima Indians ${ }^{13,14}$ ) confirm that subjects go through a period of hyperinsulinaemia before the development of NIDDM, when insulin levels fall.

\section{Insulin resistance, hyperinsulinaemia and hypertension}

Several reports indicate that patients with raised blood pressure have abnormalities in glucose and insulin metabolism. Both untreated and treated hypertensive subjects have higher insulin levels and are relatively glucose intolerant compared with individuals with normal blood pressure. ${ }^{15}$ Clamp studies indicate that these groups are more resistant to the action of insulin. ${ }^{16-19}$ As before, hyperinsulinaemia is considered to be a consequence of the insulin resistant state.

There is indirect evidence that insulin resistance and hyperinsulinaemia may be relevant to the aetiology of hypertension. For example, there is a correlation between plasma insulin concentration and the level of blood pressure ${ }^{20}$ and there is an increased prevalence of hypertension in patients with NIDDM. ${ }^{21}$ Further, experimental data suggest mechanisms whereby hyperinsulinaemia may raise blood pressure. Insulin is known to stimulate the sympathetic nervous system, resulting in a significant elevation in plasma catecholamine concentrations. ${ }^{22,23}$ The sodium-retaining properties of insulin, probably acting at the level of the proximal tubule, are also well documented. ${ }^{24,25}$ This should increase total exchangeable body sodium, as well as total vascular volume, and in NIDDM increased total body sodium is a consistent finding. ${ }^{26}$ Increased total body exchangeable sodium has also been reported in patients with essential hypertension. ${ }^{27}$ Further support comes from the hypotensive effect of diuretics (which promote sodium excretion) and dietary sodium restriction in hypertensive diabetics. ${ }^{28}$
Insulin resistance, hyperinsulinaemia and coronary artery disease

Abnormal glucose tolerance, both NIDDM and IGT, ${ }^{29,30}$ and hypertension are well known coronary risk factors. There is also evidence to suggest that other variables of Syndrome $X$ promote coronary risk. At least three prospective epidemiological studies have shown that hyperinsulinaemia is associated with increased risk of developing $\mathrm{CAD}^{31-33}$ and levels of HDL-cholesterol (HDL-C) are inversely related to coronary events in both males and females. ${ }^{34}$ The data concerning raised triglycerides are less clear. Two other studies have shown triglycerides to be an independent risk factor; both considered diabetic populations only and neither measured HDL-C. ${ }^{35,36}$ However, in combination with low HDL-C it is likely that raised triglycerides warrant attention.

We have seen how both abnormal glucose tolerance and hypertension might be associated with insulin resistance. Low HDL-C and increased VLDL concentrations may also be a feature of insulin resistance, since the major clearance enzyme of triglyceride-rich particles in the periphery is insulin-sensitive lipoprotein lipase ${ }^{37}$ Indeed, there are reports of hypertriglyceridaemia and low HDLcholesterol concentrations in association with hyperinsulinaemia. ${ }^{38}$ Therefore, Reaven's hypothesis proposes a group of cardiovascular risk factors, all of which may be a consequence of the insulin resistant state.

The mechanisms by which elements of Syndrome $X$ could promote the formation of coronary atheroma are not clear. Insulin resistance, genetically acquired and/or environmentally induced, could be the true aetiological factor and other components of the syndrome simply epiphenomena. Alternatively, hyperinsulinaemia may be of crucial importance; insulin is a potent stimulus to endothelial cell growth $^{39}$ and also regulates low density lipoprotein (LDL)-receptor activity. ${ }^{40,41}$ Similarly, glucose intolerance is associated with abnormalities of platelet function, glycation of lipoproteins and the formation of lipid peroxides, all of which might promote atherogenesis. ${ }^{42-44}$

\section{Implications with regard to treatment}

The concept of a cardiovascular risk factor complex has important therapeutic implications. Agents used to correct one variable, for example hypertension, should not adversely affect another since the beneficial effects of treatment may then be negated. Indeed, if Reaven's hypothesis is completely accepted then the most important aspect of therapy is that it does not worsen the insulin resistant state. 


\section{Hypertension}

The disappointing results, in terms of cardiovascular mortality, from trials of antihypertensive therapy may be a consequence of the adverse effects of the agents used on other components of Syndrome $\mathrm{X}$. Indeed, the hypothesis emphasizes the importance of non-pharmacological treatment of hypertension. Weight reduction and dietary manipulation (increasing fibre, reduction of fat and sodium intake) are especially prudent, since these measures reduce both blood pressure and insulin resistance. ${ }^{45,46}$ Regular exercise also increases insulin sensitivity and has beneficial effects on other aspects of the syndrome. ${ }^{47}$

Regarding the Syndrome X hypothesis, thiazide diuretics appear to be the least attractive of the antihypertensive drugs. These agents promote the development of glucose intolerance $e^{48-50}$ and have been shown to increase insulin resistance. ${ }^{51}$ Beta blockers are also known to worsen glucose tolerance, especially in combination with diuretics, ${ }^{48}$ and they cause a rise in triglyceride levels in association with a fall in HDL-C concentration. ${ }^{52}$ Atenolol and metoprolol have now been shown to worsen insulin resistance in clamp studies. ${ }^{53}$

Newer antihypertensive agents have potential advantages over diuretics and beta-blockers. Angiotensin converting enzyme (ACE)-inhibitors do not raise serum insulin levels and have neutral effects on lipoproteins. Captopril has been shown to reduce insulin resistance in euglycaemic hyperinsulinaemic clamp studies. ${ }^{51}$ Alpha-blockers improve the cardiovascular risk profile by lowering LDL cholesterol ${ }^{54}$ and prazosin has also been reported to increase insulin sensitivity. ${ }^{55}$

Calcium antagonists, in animal experiments, impair insulin release from the pancreas ${ }^{56}$ and this might be expected to aggravate an already insulin resistant state. However, euglycemic clamp studies with diltiazem show that this drug has no effect on insulin sensitivity ${ }^{57}$ In clinical practice, elevation of blood glucose is negligible and no major changes in serum lipids have been observed. ${ }^{54}$

\section{Non-insulin-dependent diabetes mellitus}

Reaven's hypothesis offers an explanation for the high level of premature cardiovascular disease in subjects with both NIDDM and IGT. Regarding therapy, the implication is that treatment directed solely at the restoration of normoglycaemia is unlikely to produce a substantial reduction in CAD. Indeed, the use of insulin in obese subjects might be discouraged since this may promote weight gain as well as increasing peripheral hyperinsulinaemia. ${ }^{58}$ Results from the UK Prospective Diabetes Study, ${ }^{2}$ in which subjects are being sub- jected to very tight glycaemic control, should establish whether these reservations are justified.

\section{Obesity}

A body mass index over $28.5 \mathrm{~kg} / \mathrm{m}^{2}$ is a marker for increased coronary mortality ${ }^{59}$ and separate associations between obesity and hyperinsulinaemia, glucose intolerance and hypertension are well documented. These findings are consistent with Reaven's hypothesis since a centripetal distribution of body fat is associated with increased insulin resistance ${ }^{60}$ Indeed, some would include obesity in the cardiovascular risk complex. ${ }^{61}$ Until recently there has been little interest in treating obesity with drugs. However, this situation may now be changing and is given impetus by the finding that anorectic drugs, which act as serotonin agonists, reduce insulin resistance. ${ }^{62}$ According to Reaven's hypothesis, these agents should improve glucose tolerance and lower blood pressure and there are confirmatory reports. ${ }^{63-65}$ Interestingly, these effects appear to occur independently of changes in body mass, implying a specific effect on insulin resistance.

\section{Is the Syndrome $\mathbf{X}$ hypothesis conclusive?}

The association of glucose intolerance, hyperinsulinaemia, lipid abnormalities and hypertension is now well described. There are, however, aspects of the hypothesis which demand clarification.

Concerning the development of NIDDM, Reaven's hypothesis proposes that hyperinsulinaemia is purely a compensatory response to peripheral insulin resistance and implies that the circulating insulin is 'normal'. The role of the pancreatic beta cell in this process is simply one of activity or exhaustion. Studies cited in support of the hypothesis have used a standard immunoassay for plasma insulin. However, it has recently been demonstrated that this assay also measures inactive molecules formed during production of insulin from pro-insulin. ${ }^{66}$ Using a highly specific two site immunoradiometric assay for insulin, some reports have suggested that some patients with NIDDM may have low levels of 'active insulin', i.e. the hyperinsulinaemia is artifactual. If this proves to be the case in the majority of subjects with NIDDM and IGT, then the pancreatic beta cell assumes a more pivotal role in the generation of glucose intolerance, as has been suggested by other authors. ${ }^{67,68}$ The primacy of insulin resistance is further questioned by reports of insulin insensitivity, at a post-receptor level, induced by high circulating levels of insulin. ${ }^{69,70}$

The relevance of resistance to insulin-mediated 
glucose uptake also deserves consideration. Reaven's hypothesis is based upon acute loading experiments, such as glucose challenge tests (oral or intravenous), glucose turnover studies using a ${ }^{3} \mathrm{H}$-glucose isotope dilution, whole body glucose oxidation using indirect calorimetry, and the euglycaemic clamp technique. ${ }^{6,9,10,13}$ Whether these short-term laboratory experiments reveal chronic insulin resistance is unclear, particularly as glucose disposal during clamp experiments may be affected by changes in peripheral blood flow.

Finally, although currently available trials of antihypertensive medication (mainly diuretics and beta blockers) have been disappointing with regard to CAD, they have demonstrated a consistent reduction in stroke morbidity and mortality of approximately $30 \% .{ }^{1}$ Indeed, a recent meta-analysis suggested that coronary deaths are reduced by

\section{References}

1. Swales, J.D., Ramsey, L.E., Coope, J.R. et al. Report of the British Hypertension Society working party. Treating mild hypertension. $\mathrm{Br}$ Med J 1989, 298: 694-698.

2. Multi-centre study. UK prospective study of therapies of maturity-onset diabetes. 1. Effect of diet, sulphonylurea, insulin or biguanide therapy on fasting plasma glucose and body weight over one year. Diabetologia 1983, 24: 404-411.

3. Reaven, G.M. Role of insulin resistance in human disease. Banting Lecture. Diabetes 1988, 37: 1595-1607.

4. DeFronzo, R.A., Tobin, J. \& Andres, R. Glucose clamp technique: a method for quantifying insulin secretion and resistance. Am J Physiol 1979, 237: E214-223.

5. Mbanya, J.C.N., Thomas, T.H., Wilkinson, 'R., Alberti, K.G.M.M. \& Taylor, R. Hypertension and hyperinsulinaemia: a relation in diabetes but not essential hypertension. Lancet 1988, i: 733-734.

6. Shen, S-W., Reaven, G.M. \& Farquhar, J. Comparison of impedence to insulin-mediated glucose uptake in normal subjects and in subjects with latent diabetes. $J$ Clin Invest 1970, 49: 2151-2160.

7. Ginsberg, H., Kimmerling, G., Olefsky, J.M. \& Reaven, G.M. Demonstration of insulin resistance in untreated adult onset diabetic subjects with fasting hyperglycaemia. J Clin Invest 1975, 55: 454-461.

8. Ginsberg, J., Olefsky, J.M. \& Reaven, G.M. Further evidence that insulin resistance exists in patients with chemical diabetes. Diabetes 1974, 23: 674-678.

9. Golay, A., Chen, Y.-D. \& Reaven, G.M. Effect of differences in glucose tolerance on insulin's ability to regulate carbohydrate and free fatty acid metabolism in obese individuals. $J$ Clin Endocrinol Metab 1986, 62: 1081-1088.

10. Hollenbeck, C. \& Reaven, G.M. Variations in insulinstimulated glucose uptake in healthy individuals with normal glucose tolerance. J Clin Endocrinol Metab 1987, 64: 11691173.

11. DeFronzo, R.A., Ferrannini, E. \& Koivisto, V. New concepts in the pathogenesis and treatment of non-insulin-dependent diabetes mellitus. Am J Med 1983, 74: 52-81.

12. Fraze, E., Donner, C.C., Swislocki, A.L.M., Chiou, Y.-A.M., Chen, Y.-D.I. \& Reaven, G.M. Ambient plasma free fatty acid concentrations in non-insulin-dependent diabetes mellitus: evidence for insulin resistance. J Clin Endocrinol Metab 1985, 61: 807-811.

13. Saad, M.F., Knowler, W.C., Pettitt, D.J., Nelson, R.G., Mott, D.M. \& Bennett, P.H. The natural history of impaired glucose tolerance in the Pima Indians. N Engl J Med 1988, 319: $1500-1506$.
$12-15 \%{ }^{71}$ and there is no evidence that these drugs are associated with increased coronary mortality, as might be expected from their effects on insulin resistance. This finding is all the more remarkable, given that diuretics also increase LDL-cholesterol levels. Furthermore, there is evidence that beta blockers are effective secondary prevention of CAD. ${ }^{72}$

Whilst newer antihypertensive agents, such as ACE-inhibitors and calcium antagonists, are theoretically attractive there is currently no evidence that these agents offer any substantial advantage in terms of cardiovascular or stroke mortality. It would therefore, be premature to abandon the use of diuretics and beta blockers on the basis of the Syndrome $\mathrm{X}$ hypothesis, a conclusion also reached in a leading article in this issue of the Journal. ${ }^{73}$

14. Saad, M.F., Knowler, W.C., Pettitt, D.J., Nelson, R.G., Mott, D.M. \& Bennett, P.H. Sequential changes in serum insulin concentration during development of non-insulin dependent diabetes. Lancet 1989, i: 1356-1359.

15. Swislocki, A.L.M., Hoffman, B.B. \& Reaven, G.M. Insulin resistance, glucose intolerance and hyperinsulinaemia in patients with hypertension. Am J Hypertens 1989, 2: 419-423.

16. Shen, D.C., Shieh, S.M., Fuh, M.M.T., Wu, D.A., Chen, Y.-D.I. \& Reaven, G.M. Resistance to insulin-stimulatedglucose uptake in patients with hypertension. $J$ Clin Endocrinol Metab 1988, 66: 580-583.

17. Ferrannini, E., Buzzigoli, G., Bonadonna, R. et al. Insulin resistance in essential hypertension. $N$ Engl J Med 1987, 317: 350-357.

18. Verza, M., D’Avino, M., Cacciapuoti, F. et al. Hypertension in the elderly is associated with impaired glucose metabolism independently of obesity and glucose intolerance. $J$ Hypertens 1988, 6 (Suppl 1): S45-S48.

19. Varricchio, M., Paolisso, G., Torella, R. \& D'Onofrio, F. Diabetes and hypertension in the elderly. $J$ Hypertens 1988,6 (Suppl 1): S41-S44.

20. Manicardi, V., Camellini, L., Belloidi, G., Coscelli, C. \& Ferrannini, E. Evidence for an assocation of high blood pressure, and hyperinsulinaemia in obese man. J Clin Endocrinol Metab 1986, 62: 1302-1304.

21. Dodson, P.M. Chapter 1. Epidemiology and pathogenesis of hypertension in diabetes mellitus. In: Barnett, A.H. (ed.) Hypertension and Diabetes. Science Press, London, 1990.

22. Rowe, J.W., Young, J.B., Minaker, K.L., Stevens, A.L., Pallotta, J. \& Landsberg, L. Effect of insulin and glucose infusions on sympathetic nervous system activity in normal mean. Diabetes 1981, 30: 219.

23. Christensen, N.J., Gundersen, H.J.G., Hegedus, L. et al. Acute effect of insulin on plasma noradrenaline and the cardiovascular system. Metabolism 1980, 29: 1138-1145.

24. DeFronza, R.A., Goldberg, M. \& Agus, Z. The effects of glucose and insulin on renal electrolyte transport. $J$ Clin Invest 1976, 58: 83-90.

25. DeFronza, R.A., Cooke, C., Andres, R., Faloona, G.R. \& David, P.J. The effect of insulin in renal handling of sodium, potassium, calcium and phosphate in man. J Clin Invest 1975, 55: $845-855$.

26. De Chatel, R., Weidmann, P. \& Flammer, J. Sodium, renin, aldosterone, catecholamines and blood pressure in diabetes mellitus. Kidney Int 1977, 12: 412-421. 
27. Beretta-Piccoli, C., Davies, D.L. \& Boddy, K. Relation of arterial pressure with body sodium, body potassium and plasma potassium in essential hypertension. Clin Sci 1982, 63: 257-270.

28. Dodson, P.M., Beevers, M., Hallworth, R., Webberley, M.J., Fletcher, R.F. \& Taylor, K.G. Sodium restriction and blood pressure in hypertensive Type II diabetics: randomised blind controlled and crossover studies of moderate sodium restriction and sodium supplementation. $B r M e d J$ 1989, 298: 227-230.

29. Garcia, M.J., McNamara, P.M., Gordon, T. et al. Morbidity and mortality in diabetics in the Framingham population: sixteen-year follow-up. Diabetes 1974, 23: 105-111.

30. Fuller, J.H., Shipley, M.J., Rose, G. et al. Coronary heart disease risk and impaired glucose tolerance. The Whitehall Study. Lancet 1980, i: 1373-1376.

31. Pyorala, K. Relationship of glucose tolerance and plasma insulin to the incidence of coronary heart disease: results from two population studies in Finland. Diabetes Care 1979, 2: $131-141$.

32. Ducimetiere, P., Eschwege, E., Papoz, L., Richard, J.L., Claude, J.R. \& Rosselin, G. Relationship of plasma insulin levels to the incidence of myocardial infarction and coronary heart disease in a middle-aged population. Diabetologia 1980 , 19: $205-210$.

33. Welborn, T.A. \& Wearne, K. Coronary heart disease and cardiovascular mortality in Busselton with reference to glucose and insulin concentrations. Diabetes Care 1979, 2: 154-160.

34. Gordon, D.J. \& Rifkind, B.M. High density lipoprotein - the clinical implications of recent studies. N Engl J Med 1989, 321: $1311-1316$.

35. West, K.M., Ahuja, M.S., Bennet, P.H. et al. The role of circulating glucose and triglyceride concentrations and their interactions with other 'risk factors' as determinants of arterial disease in nine diabetic population samples from the WHO multinational study. Diabetes Care 1983, 6: 361-369.

36. Fontbonne, A., Eschwege, E., Cambien, F. et al. Hypertriglyceridaemia as a risk factor of coronary heart disease mortality in subjects with impaired glucose tolerance or diabetes. Diabetologia 1989, 32: 300-304.

37. Dodson, P.M. Lipids, lipoproteins and diabetes mellitus. In: Taylor, K.G. (ed.) Diabetes and the Heart, Chapter 4. Castle House Publications, Tunbridge Wells, Kent, 1987.

38. Durrington, P.N. Serum high density lipoprotein cholesterol in diabetes mellitus: an analysis of factors which influence its concentration. Clin Chim Acta 1980, 104: 11-23.

39. Stout, R.W., Bierman, E.L. \& Ross, R. The effect of insulin on the proliferation of cultured primate arterial smooth muscle cells. Circ Res 1975, 36: 319-327.

40. Chait, A., Bierman, E.L. \& Albers, J.J. Regulatory role of insulin in the degradation of low density lipoprotein by cultured human skin fibroblasts. Biochem Biophys Acta 1978, 529: 292-299.

41. Chait, A., Bierman, E.L. \& Alberts, J.J. Low density lipoprotein receptor activity in fibroblasts cultured from diabetic donors. Diabetes 1979, 28: 914-918.

42. Colewell, J.A., Winocour, P.D., Lopes-Virella, M. \& Halushka, P.V. New concepts about the pathogenesis of atherosclerosis in diabetes mellitus. Am J Med 1983, 75: 67-80.

43. Steinbrecher, U.P. \& Witztum, J.L. Glucosylation of lowdensity lipoproteins to an extent comparable to that seen in diabetes slow their catabolism. Diabetes 1984, 33: 130-134.

44. Kaji, H., Kurasaki, M., Ito, K. et al. Increased lipoperoxide value and glutathione peroxidase activity in blood plasma of type 2 (non-insulin-dependent) diabetic women. Klin Wochenschr 1985, 63: 765-768.

45. Dodson, P.M., Pacy, P.J., Bal, P., Kubicki, A.J., Fletcher, R.F. \& Taylor, K.G. A controlled trial of a high fibre, low fat and low sodium diet for mild hypertension in type 2 (non-insulin-dependent) diabetic patients. Diabetologia 1984, 27: $522-526$
46. Simpson, R.W., Mann, J.I., Eaton, J., Moore, R.A., Carter, R. \& Hockaday, T.D.R. Improved glucose control in maturity-onset diabetes treated with high-carbohydrate-modified fat diet. $\mathrm{Br}$ Med J 1979, 1: 1753-1756.

47. Jennings, G., Nelson, L., Nestel, P. et al. The effects of changes in physical activity on major cardiovascular risk factors, hemodynamics, sympathetic function and glucose utilisation in man: a controlled study of four levels of activity. Circulation 1986, 73: 30-40.

48. Bengtsson, C., Blohme, G., Lapidus, L. et al. Do antihypertensive drugs precipitate diabetes? $\mathrm{Br}$ Med J 1984, 289: 1495-1497.

49. Murphy, M.C., Lewis, P.J., Kohner, E. et al. Glucose intolerance in hyertensive patients treated with diuretics: a fourteen year follow-up. Lancet 1982, ii: 1293-1295.

50. Struthers, A.D., Murphy, M.B. \& Dollery, C.T. Glucose tolerance during antihypertensive therapy in patients with diabetes mellitus. Hypertension 1985, 7 (Suppl 2): 95-101.

51. Pollare, T., Lithell, H.\& Berne, C. A comparison of the effects of hydrochlorothiazide and captopril on glucose and lipid metabolism in patients with hypertension. $N$ Engl $J$ Med 1989, 321: 868-873.

52. Northcote, R.J. Beta blockers, lipids and coronary atherosclerosis: fact or fiction? Br Med J 1988,. 296: 731-732.

53. Pollare, T., Lithell, H., Selinus, I. \& Berne, C. Sensitivity to insulin treatment with atenolol and metoprolol: a randomised, double blind study of effects on carbohydrate and lipoprotein metabolism in hypertensive patients. Br Med J 1989, 298: 1152-1157.

54. Sorkin, E.M., Clissold, S.P. \& Brogden, R.N. Nifedipine: a review of its pharmacodynamic and pharmacokinetic properties and therapeutic efficacy in ischaemic heart disease, hypertension and cardiovascular drugs. Drugs 1985, 30: $182-283$.

55. Pollare, T., Lithell, H., Morlin, C., Prantare, H., Hvarfner, A. \& Ljunghall, S. Metabolic effects of diltiazem and atenolol: results from a randomized, double-blind study with parallel groups. J Hypertens 1989, 7: 551-559.

56. Barnett, A.H. \& Kendall, M.J. Chapter 4. Pharmacology of antihypertensive drugs. In: Barnett, A.H. \& Dodson, P.M. (eds) Hypertension and Diabetes. Science Press, London, 1990.

57. Pollare, T., Lithell, H., Selinus, I. \& Beone, C. Application of prazosin is associated with an increase of insulin sensitivity in obese patients with hypertension. Diabetologia 1988, 31: $415-420$.

58. The DCCT research group. Weight gain associated with intensive therapy in the Diabetes Control and Complications Trial. Diabetes Care 1988, 11: 567-573.

59. Tuomilehto, J. Salonen, J.T., Marti, B. et al. Body weight and risk of myocardial infarction and death in the adult population of eastern Finland. $\mathrm{Br}$ Med J 1987, 295: 623-627.

60. Landin, K., Krotkiewski, M. \& Smith, U. Importance of obesity for the metabolic abnormalities associated with an abdominal fat distribution. Metabolism 1989, 38: 572-576.

61. Zimmet, P. Non-insulin-dependent (type 2) diabetes mellitus: does it really exist? Diabetes Med 1989, 6: 728-735.

62. Pestell, R.G., Crock, P.A., Ward, G.M., Alford, F.P. \& Best, J.D. Fenfluramine increases insulin action in patients with NIDDM. Diabetes Care 1989, 12: 252-258.

63. Turtle, J.R. \& Burgess, J.A. Hypoglycaemic action of fenfluramine in diabetes mellitus. Diabetes 1973, 22: 858-867.

64. Doar, J.W.H., Thompson, M.E., Wilde, C.E. \& Sewell, P.F.J. The influence of fenfluramine on oral glucose tolerance tests, plasma sugar and insulin levels in newly diagnosed late-onset diabetic patients. Curr Med Res Opin 1979, 6 (Suppl 1): 247-254.

65. Hudson, K.D., The anorectic and hypotensive effect of fenfluramine in obesity. $J R$ Coll Gen Pract 1977, 27: 497-501.

66. Temple, R.C., Luzio, S.D., Schneider, A.E. et al. Insulin deficiency in non-insulin-dependent diabetes. Lancet 1989, i: 293-295. 
67. O'Rahilly, S.P., Nugent, Z., Rudenski, A.S. et al., Beta-cell dysfunction, rather than insulin deficiency, is the primary defect in familial type 2 diabetes. Lancet 1986, ii: 360-364.

68. Cahill, G.F. Beta-cell deficiency, insulin resistance, or both? $N$ Engl J Med 1988, 318: 1268-1269.

69. Marangou, A.G., Weber, K.M., Boston, R.C. et al. Metabolic consequences of prolonged hyperinsulinaemia in humans. Diabetes 1986, 35: 1383-1389.

70. Rizza, R.A., Mandarino, L.J., Genest, J., Baker, B.A. \& Gerich, J.E. Production of insulin resistance by hyperinsulinaemia in man. Diabetologia 1985, 28: 70-75.
71. Collins, R., Peto, R., MacMahon, S. et al. Blood pressure, stroke and coronary heart disease. Part 2, short term reductions in blood pressure: overview of randomised drug trials in their epidemiological context. Lancet 1990, i: 827-838.

72. Kjekshus, J., Gilpin, E., Cali, G., Blackey, A.R., Henning, H. \& Ross, J. Jr. Diabetic patients and beta-blockers after acute myocardial infarction. Eur Heart $J$ 1990, 11: 43-50.

73. Rutherford, P.A., Thomas, T.H. \& Wilkinson, R. Insulin resistance and hypertension - implications for treatment. Postgrad Med J 1991, 67: 869-875. 